\title{
Modulation of the critical flicker fusion effects of serotonin reuptake inhibitors by concomitant pupillary changes.
}

Citation for published version (APA):

Schmitt, J. A. J., Riedel, W. J., Vuurman, E. F. P. M., Kruizinga, M., \& Ramaekers, J. G. (2002). Modulation of the critical flicker fusion effects of serotonin reuptake inhibitors by concomitant pupillary changes. Psychopharmacology, 160, 381-386. https://doi.org/10.1007/s00213-001-0993-y

Document status and date:

Published: 01/01/2002

DOI:

10.1007/s00213-001-0993-y

Document Version:

Publisher's PDF, also known as Version of record

Document license:

Taverne

Please check the document version of this publication:

- A submitted manuscript is the version of the article upon submission and before peer-review. There can be important differences between the submitted version and the official published version of record.

People interested in the research are advised to contact the author for the final version of the publication, or visit the DOI to the publisher's website.

- The final author version and the galley proof are versions of the publication after peer review.

- The final published version features the final layout of the paper including the volume, issue and page numbers.

Link to publication

\footnotetext{
General rights rights.

- You may freely distribute the URL identifying the publication in the public portal. please follow below link for the End User Agreement:

www.umlib.nl/taverne-license

Take down policy

If you believe that this document breaches copyright please contact us at:

repository@maastrichtuniversity.nl

providing details and we will investigate your claim.
}

Copyright and moral rights for the publications made accessible in the public portal are retained by the authors and/or other copyright owners and it is a condition of accessing publications that users recognise and abide by the legal requirements associated with these

- Users may download and print one copy of any publication from the public portal for the purpose of private study or research.

- You may not further distribute the material or use it for any profit-making activity or commercial gain

If the publication is distributed under the terms of Article $25 \mathrm{fa}$ of the Dutch Copyright Act, indicated by the "Taverne" license above, 
Jeroen A.J. Schmitt • Wim J. Riedel

Eric F.P.M. Vuurman · Monique Kruizinga

Johannes G. Ramaekers

\section{Modulation of the Critical Flicker Fusion effects of serotonin reuptake inhibitors by concomitant pupillary changes}

Received: 6 August 2001 / Accepted: 21 November 2001 / Published online: 7 February 2002

(C) Springer-Verlag 2002

\begin{abstract}
Rationale: Serotonin reuptake inhibitors (SSRIs) have been attributed CNS-activating properties based on their ability to elevate the Critical Flicker Fusion (CFF) threshold. However, such an interpretation may be questioned since CFF elevations may also be due to SSRIinduced increases in pupil diameter. Objectives: The effect of pupillary changes on CFF assessment following SSRI administration was investigated in a double blind, crossover study. Methods: During three periods of 15 days, 21 healthy men and women (30-50 years) received sertraline $(50 \mathrm{mg}$ on days $1-8,100 \mathrm{mg}$ on days $9-15)$, citalopram (20 $\mathrm{mg}$ on days $1-8,40 \mathrm{mg}$ on days 9-15) and placebo. Assessments were done on days 1,8 and 15 and consisted of pupillary measurements and CFF assessments with and without pupillary control (a 2-mm artificial pupil) using the Leeds Psychomotor Tester. Results: Both SSRIs induced an acute and steady increase in pupil diameters. CFF thresholds were depressed following acute administration of sertraline and citalopram, but this was only apparent when a control was made for the pupillary changes. No CFF effects were seen at day 8 , but CFF was again reduced at day 15, with and without control for pupil size. Conclusions: Mydriasis masked the detrimental effects of both SSRIs on CFF during the acute assessments. Our results raise questions regarding the validity of the assessment of the behavioural toxicity of SSRIs based on CFF measurements without ample control for pupil size, especially when these concern acute measurements.
\end{abstract}

\footnotetext{
J.A.J. Schmitt (

Department of Psychiatry and Neuropsychology (DRT10), Universiteit Maastricht, P.O. Box 616, 6200 MD Maastricht, The Netherlands e-mail: j.schmitt@np.unimaas.nl Tel.: +31-43-3881036, Fax: +31-43-3671096
}

J.A.J. Schmitt · W.J. Riedel · E.F.P.M. Vuurman · M. Kruizinga J.G. Ramaekers

Experimental Psychopharmacology Unit,

Brain and Behaviour Institute, Universiteit Maastricht, Maastricht, The Netherlands
Keywords Sertraline $\cdot$ Citalopram $\cdot$ Cognition $\cdot$ Pupil drug effect · Drugs adverse effect $\cdot$ Critical Flicker Fusion

\section{Introduction}

The Critical Flicker Fusion (CFF) threshold is the frequency at which a flickering light is perceived as a steady light source. Changes in CFF are thought to be indicative of changes in CNS activation (Curran 1990) and CFF has been used extensively to assess the cognitive (side) effects of a variety of drugs, including antidepressants. It has been argued that CFF should be included as a primary measure in clinical trails of antidepressants (Hindmarch 1987), and CFF changes have been repeatedly used to rank the behavioural toxicity of antidepressant drugs (Hindmarch 1995, 1998, 1999; Kerr et al. 1991).

One particular class of antidepressant drugs, the serotonin reuptake inhibitors (SSRIs), were repeatedly shown to increase CFF thresholds (for reviews see Hindmarch 1995, 1999), and it was concluded based on these findings that SSRIs have 'excitatory' rather than sedative properties. However, in the case of SSRIs, CFF measurements may not be readily interpretable in terms of cognitive changes, because mydriatic (pupil dilatation) effects of SSRIs may have significantly modified the outcome of CFF measurements (Ramaekers et al. 1995; Warrington et al. 1989).

In humans, SSRIs such as paroxetine, fluoxetine and sertraline have been shown to induce significant increases in pupil diameter (Deijen et al. 1989; Ramaekers et al. 1995; Saletu and Grünberger 1988). Pupil size determines the amount of retinal illumination (Hart 1992), and as is stated by the Ferry-Porter Law (Davson 1976), CFF is directly proportional to the logarithm of the light intensity. As a consequence, CFF thresholds will rise following mydriasis and fall following miosis, as was convincingly demonstrated by Lawrence et al. (1982) using pilocarpine and homatropine eye drops to produce mio- 
sis and mydriasis, respectively. Hence, SSRIs may elevate $\mathrm{CFF}$ thresholds as a direct result of their mydriatic properties (Ramaekers et al. 1995; Warrington et al. 1989). As a consequence, CFF thresholds obtained after SSRI administration are likely to reflect a combination of arousal/CNS-mediated changes and those attributable to pupil dilatation.

The need for pupillary control in CFF testing, particularly in psychopharmacology research, has been frequently pointed out (AufdemBrinke 1982; Danjou et al. 1992; Lawrence et al. 1982; Smith and Misiak 1976). Concomitant mydriatic effects may lead to a wrongful favourable representation of a drugs cognitive profile, or may even mask a drug's detrimental effect on CNS activation, whereas miotic effects may be misinterpreted as sedative actions. Nevertheless, a pupillary control is rarely used in studies measuring the CFF effects of psychoactive drugs, despite the fact that an effective control for pupillary changes is fairly easy implemented by the use of a 2-mm artificial pupil (Smith and Misiak 1976). It is noteworthy that those investigators who made the effort to control for pupil size (Mattila et al. 1988; Ramaekers et al. 1995) were unable to detect the ascribed CFF elevation after SSRI administration.

The present experiment was carried out to examine the effect of pupillary changes on CFF measurements following SSRI administration. This was investigated by the assessment of the acute and subchronic effects of the SSRIs sertraline and citalopram on CFF threshold, obtained with and without a 2-mm artificial pupil to control for pupil dilatation. Sertraline and citalopram are predicted to increase pupil size and consequently elevate CFF when assessed without pupillary control, but no effects are expected when CFF is assessed with a control for pupil size.

\section{Materials and methods}

\section{Subjects}

Twenty-four healthy subjects, 12 men and 12 women, aged 30-50 years, were recruited through newspaper advertisements. Subjects were screened by means of a telephonic interview, health questionnaire, electrocardiogram, laboratory tests (blood haematology and chemistry, urinalysis, drug and pregnancy screening) and a routine medical examination. Exclusion criteria were the presence or a history of cardiac, hepatic, renal, pulmonary, neurological, gastrointestinal, haematological or psychiatric illness, symptoms of excessive drinking (>20 units of alcoholic beverage a week), pregnancy or lactation, use of medication other than oral contraceptives, use of drugs, and any sensory or motor deficits which could reasonably be expected to affect test performance. All subjects scored below depression threshold $(<50)$ on the Zung Depression Scale (Zung 1965). The study was approved by the standing Medical Ethics Committee of Maastricht University, and carried out in accordance with the Declaration of Helsinki (Hong Kong Modification 1989). Written informed consent was obtained from each subject prior to participation.

\section{Design and treatments}

The study was conducted according to a randomised, doubleblind, placebo-controlled three-period crossover design. Treatment

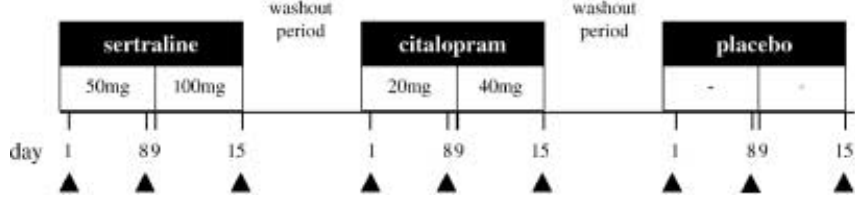

Fig. 1 Schematic representation of the study design, with an example of a treatment order (sertraline-citalopram-placebo). Dosage for each treatment was doubled on days 9-15. Triangles denote the time points of assessments (days 1,8 and 15)

orders were randomly assigned and double blind. Treatment periods lasted 15 days and were separated by 14-day washout periods. Treatment regimens consisted of sertraline $50 \mathrm{mg}$ on days $1-8$ followed by sertraline $100 \mathrm{mg}$ on days $9-15$, citalopram $20 \mathrm{mg}$ on days $1-8$ followed by citalopram $40 \mathrm{mg}$ on days $9-15$, or placebo (Fig. 1). Medication was taken at fixed times in the morning.

\section{Testing procedure}

Assessments were done on days 1,8 and 15 of each treatment period at a fixed time between 12 noon and 6 p.m. The acute measurements on day 1 were done $5 \mathrm{~h}$ after the first drug administration. Before the start of the study, all subjects were individually trained to conduct the CFF tests. Consumption of alcoholic beverages during the treatment periods was prohibited and subjects were instructed to arrive at the laboratory well rested. Female subjects were tested for pregnancy before the start of each of the three treatment periods. CFF assessments were first performed without pupillary control, followed by a similar assessment with a 2-mm artificial pupil. Lastly, pupil diameter was measured. The entire procedure lasted approximately $10 \mathrm{~min}$.

\section{Critical Flicker Fusion assessment}

CFF was assessed using the Leeds Psychomotor Tester (Leeds Psychomotor Services, York). CFF threshold was ascertained using four red light-emitting diodes in a binocular foveal fixation, positioned at eye level, with dimmed ambient illumination. Responses were made through a push button, which was attached to the emitting device by a 1-m-long wire. This ensured that the subject viewed the stimuli from a standard distance. In the condition with pupillary control, the subjects wore closed eyeglasses with two 2-mm apertures, which could be adjusted to match the position of each subject's eyes.

The psychophysical method of limits was used to determine CFF thresholds, with three alternating ascending and descending trials. In the ascending mode, flicker was increased by $1 \mathrm{~Hz} / \mathrm{s}$ and subjects had to press the button when they could no longer detect flickering. In the descending mode, the flicker frequency was gradually decreased by $1 \mathrm{~Hz} / \mathrm{s}$ and subjects responded when they just started to see a flickering. The mean of the six measurements was taken as the dependent variable indicating CFF threshold.

CFF is most often interpreted in terms of a CNS arousal and activation (Curran and Wattis 1998). CFF shifts, however, may also occur as a result of changes in a subjects' response criterion, particularly when CFF is determined by the method of limits paradigm (Clark 1966). In short, a more conservative response strategy may lead to a CFF reduction, whereas a riskier response strategy can result in CFF elevations (see Ghozlan 1990; Ghozlan and Widlöcher 1993; MacNab et al. 1985). To exclude effects of response bias, a forced-choice paradigm may be employed (Swets et al. 1961). However, in psychopharmacology research, the Leeds Psychomotor Tester and the method of limits paradigm is used extensively, and to ensure comparability with previous studies this methodology was used in the present study as well. However, in order to investigate if changes in response bias had influenced the threshold assessment, the difference between mean ascending $\left(f_{\mathrm{a}}\right)$ 
and descending thresholds $\left(f_{\mathrm{b}}\right)$ was calculated. The ascending-descending threshold difference $\left(\Delta=f_{\mathrm{a}}-f_{\mathrm{b}}\right)$ is thought to reflect the internal subjective judgement of subjects; a more conservative response criterion will result in a larger value of $\Delta$ (Ghozlan 1990; Ghozlan and Widlöcher 1993).

\section{Pupil diameter}

Pupil diameter was recorded using a head-mounted eye-tracking system (4000SU eye tracker; Applied Science Laboratories). The beam from an infrared light source illuminates the eye and an optical system focuses an image of the pupil onto a solid-state eye camera. Both the illumination beam and the image of the eye are reflected from a helmet visor, which is coated to be reflective in the near infrared region and transitive to visible light. The illuminator, optics and camera are all helmet mounted. Pupil and corneal reflection outlines and centroids are displayed on a pupil monitor over the video image of the eye. Pupillary diameter was recorded for approximately $10 \mathrm{~s}$ at a rate of 50 measurements per second. Median pupil diameter is taken as the dependent variable.

\section{Statistical analyses}

Pupil diameters were analysed in a multivariate, repeated-measures analysis of variance (MANOVA) according to a $3 \times 3$ factorial design. Within-subjects factors were Treatment (placebo, sertraline, citalopram) and Time (days 1, 8, 15). CFF thresholds were analysed using a MANOVA according to a $3 \times 3 \times 2$ factorial design, with Treatment (placebo, sertraline, citalopram), Time (days 1, 8, 15) and Pupillary control (present, absent) as within-subjects factors. Significant $(P<0.05)$ main effects involving factors with more than two levels (i.e. Treatment and Time) or interaction effects were further investigated using separate comparisons (paired $t$-tests) between the appropriate levels to identify the exact nature of the differences.

\section{Results}

\section{Missing data}

Three subjects (one man, two women) withdrew from the study after experiencing nausea and diarrhoea following administration of citalopram. Data from the remaining 21 subjects were analysed and are reported below.

\section{Pupil diameter}

Results of the pupil measurements are depicted in Fig. 2. Overall analysis of the pupil diameters showed a main effect of Treatment $[F(2,19)=39.96, P<0.001]$, but no main effect of Time or a Treatment by Time interaction. Subsequent comparisons revealed that sertraline $[t(20)<-3.45$, $P<0.005]$ and citalopram $[t(20)<-4.39, P<0.001]$ induced a significant increase of pupil diameter compared to placebo at each time point. Pupil diameters did not differ, however, between sertraline and citalopram at any point.

\section{Critical Flicker Fusion}

Results of the CFF assessments are presented in Fig. 3. CFF thresholds showed a main effect of Pupillary control $[F(1,20)=208.82, P<0.001]$ and a main effect of

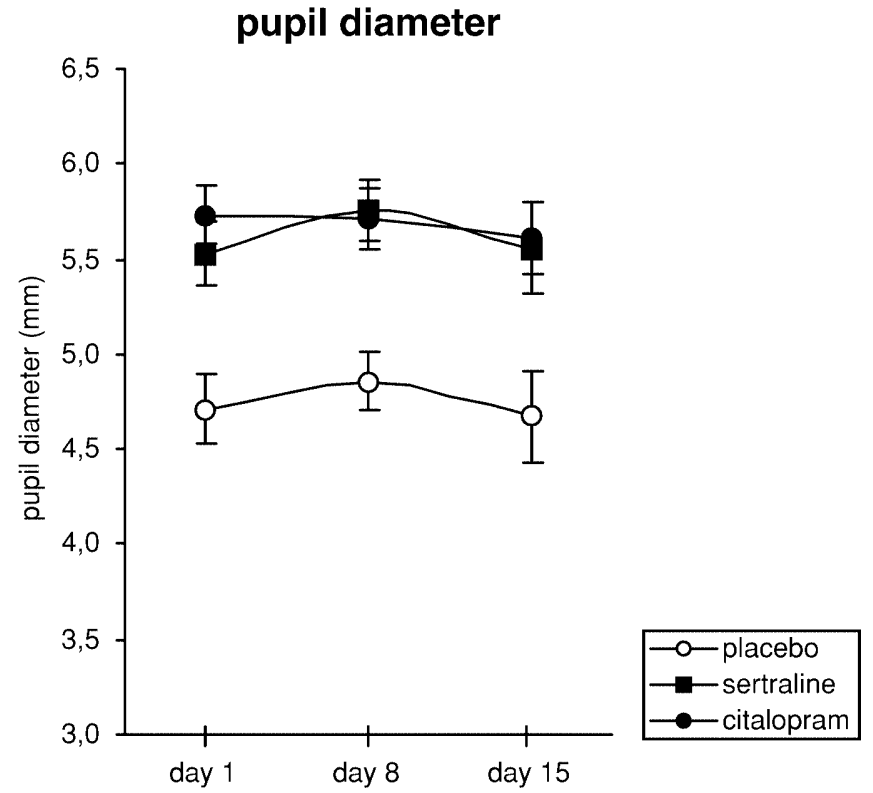

Fig. 2 Mean (standard error) pupil diameter after 1, 8 and 15 days of treatment with placebo, sertraline and citalopram

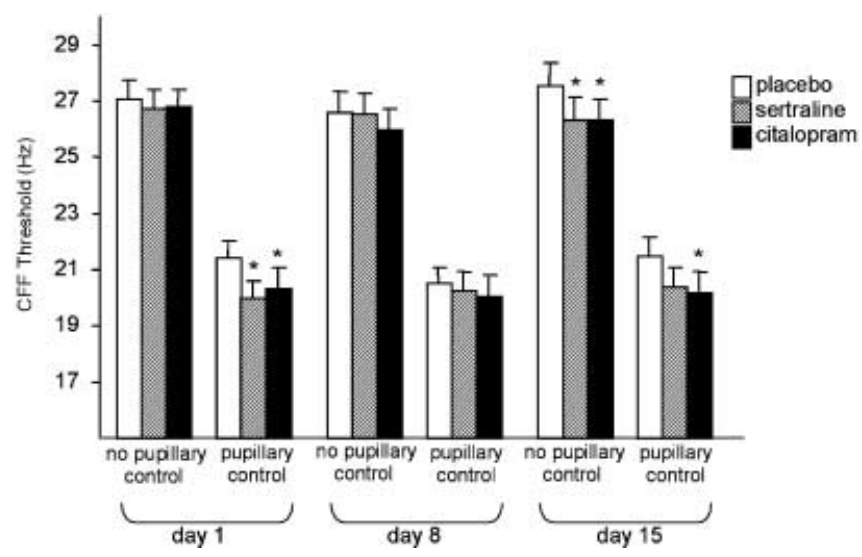

Fig. 3 Mean (standard error) Critical Flicker Fusion $(C F F)$ thresholds as measured with the Leeds Psychomotor Tester with and without a 2-mm artificial pupil to control for pupil size, on days 1,8 and 15 of treatment with placebo, sertraline and citalopram. $* P<0.05$ versus placebo

Treatment $[F(2,19)=6.68, P<0.01]$, whereas the main effect of Time approached significance $[F(2,19)=3.36$, $P<0.06]$. No interaction effects were found. Further analyses showed that at day 1 , sertraline $[t(20)=2.59$, $P<0.05]$ and citalopram $[t(20)=2.67, P<0.05]$ significantly reduced CFF when assessed with pupillary control, but no such reduction was found in the CFF assessment without pupillary control. At day 8, no effects of either drug were seen, with or without pupillary control. At day 15 , citalopram decreased CFF obtained with $[t(20)=$ $2.24, P<0.05]$ and without $[t(20)=2.72, P<0.05]$ pupillary control. Similarly, sertraline reduced CFF without pupillary control $[t(20)=2.41, P<0.05]$, whereas the reduction of CFF with pupillary control just failed to reach significance $[t(20)=1.90, P=0.07]$. 


\section{Response criterion}

Analysis of the calculated differences between mean ascending and descending thresholds $(\Delta)$ revealed no main effects of Treatment or Time. A main effect was present for Pupillary control $[F(1,20)=20.06, P<0.001]$ indicating that differences were larger in the uncontrolled condition. No interaction effects were found.

\section{Discussion}

As was hypothesised, pupil diameter increased significantly during treatment with sertraline and citalopram. Mydriasis occurred quite rapidly following a single acute dose of both SSRIs, reaching a maximum $5 \mathrm{~h}$ after first administration. Subsequently, mydriasis remained stable at this level throughout the treatment period. While mydriasis following sertraline administration has been found previously (Saletu and Grünberger 1988), this is the first study to demonstrate the mydriatic effect of citalopram.

The role of a serotonergic mechanism in the control of pupillary diameter has also been suggested by the actions of serotonergic drugs other than SSRIs. It has been reported that $5 \mathrm{HT}_{2}$ receptor antagonists (Millson et al. $1991,1992)$ and $5 \mathrm{HT}_{3}$ receptor antagonists (Rizzi et al. 1993) cause miosis. In contrast, fenfluramine, m-chlorophenylpiperazine and $5-\mathrm{HT}_{1 \mathrm{~A}}$ receptor agonists were shown to increase pupil size (Benjamin et al. 1997; Broocks et al. 1998; Prow et al. 1996). The mydriatic response is probably mediated by central $5 \mathrm{HT}_{1 \mathrm{~A}}$ receptors evoking the release of noradrenaline on alpha2-adrenoreceptors (Prow et al. 1996). Activation of postsynaptic alpha2-adrenoreceptors at the Edinger-Westphal nucleus inhibits parasympathetic activation of the constrictor muscles in the iris, leading to mydriasis (Szabadi and Bradshaw 1996).

The main finding in the present study is that mydriasis significantly affected the outcome of CFF assessments following SSRI administration. An acute dose of $50 \mathrm{mg}$ sertraline and $20 \mathrm{mg}$ citalopram was found to decrease CFF thresholds when controlled for pupil size. At the same time, no such a decrease was seen in the CFF assessment without pupillary control, suggesting that the concomitant increase in pupil size had attenuated a decline in CFF. Our data also indicate that the influence of mydriasis on CFF is limited to the acute assessment; the ensuing (subchronic) measurements revealed no differences in CFF results obtained with or without a pupillary control. Both methods of assessment show that CFF was unchanged after 1 week of SSRI administration, while doubling of the dosage to $100 \mathrm{mg}$ sertraline and $40 \mathrm{mg}$ citalopram in the following week resulted in a reduction of CFF. It thus appears that the predicted modulation of CFF effects of sertraline and citalopram administration by concomitant mydriasis is only evident during acute assessments.
The absence of a mydriatic influence on subchronic CFF assessments results is rather unexpected and cannot be explained by variations in pupil diameter, since pupils remained steadily enlarged during the full length of SSRI treatment periods. Possibly, a prolonged increase in retinal illumination due to mydriasis induces an adaptive response in subsequent sensory pathways. For example, it was found that long-term exposure to bright ambient light produced morphological and biochemical adaptations of the retina in rats to 'regulate the number of photons captured a day and protect against light damage' (reviewed by Penn and Anderson 1991). Adaptation to luminance might be expected to disturb the relation between pupil size and CFF (Ripps and Weale 1976). Indeed, CFF threshold shows no correlation with the natural size of the pupil (Miles 1950).

Experimental data on the CFF effects of sertraline reveals a clear distinction between acute and subchronic results. Sertraline was found to produce CFF elevations in acute studies (Hindmarch and Bhatti 1988; Mattila et al. 1988; Saletu and Grünberger 1988), but not following subchronic treatment (Hindmarch et al. 1990; Williams et al. 1996). The only study to date on the effect of citalopram on CFF also showed an acute elevation of CFF following a single (20-mg) dose (Nathan et al. 2000). All assessments in the previous studies were done without control for pupillary changes. Interestingly, the only acute CFF study with a pupillary control failed to find a CFF elevation by sertraline (Mattila et al. 1988) Furthermore, the CFF elevations were accompanied by contradicting subjective reports of increased feelings of drowsiness (Hindmarch and Bhatti 1988; Mattila et al. 1988; Saletu and Grünberger 1988). These results support the notion that these acute CFF elevations may be due to mydriasis rather than reflect true behavioural changes.

Turning to the present data, the use of an artificial pupil presumably removes peripheral confounding by pupil changes and provides CFF data that is interpretable as a behavioural measure. Our results indicate that sertraline and citalopram exert an acute mild detrimental effect on CNS activation. Analyses indicate that the CFF reduction cannot be explained by drug-induced changes in response criterion. Subchronically, the data suggest habituation to the detrimental effects after 1 week of treatment. However, increasing the dose may have triggered the reappearance of detrimental effects at week 2 , but since no acute effect of the doubled dose was measured, this explanation needs to be confirmed in future studies. The results are in line with a previous finding of slightly reduced vigilance, as assessed with the Mackworth Clock Test, following sertraline administration (Schmitt and Riedel 1999), and with frequently reported feelings of drowsiness (Hindmarch and Bhatti 1988; Hindmarch et al. 1990; Mattila et al. 1988; Saletu and Grünberger 1988). A similar association between a decline in CFF (controlled for pupil size) and reduction of vigilance was observed with the SSRI fluoxetine (Ramaekers et al. 1995). Parallel results of controlled (but not uncon- 
trolled) CFF and other objective and subjective measures of arousal/sedation support the notion that CFF can be taken as an indicator of the effects of SSRIs on CNS arousal, but only when an effective control is made for changes in pupil size.

In conclusion, the present study demonstrated that mydriatic effects of the SSRIs sertraline and citalopram significantly modified the outcome of CFF assessments. Our data show that concurrent mydriasis masked the detrimental effects of both SSRIs on CFF during the acute assessments. Similar confounding is likely to occur with other SSRIs, and indeed with all drugs which intrinsically alter pupil size. Future CFF studies should include an effective control for pupil size or at least take into account the putative effect of pupillary changes following drug administration when interpreting the results. Our results raise questions regarding the validity of the assessment of the behavioural toxicity of SSRIs based on CFF measurements without ample control for pupil size, especially when these concern acute measurements. A critical reappraisal of the data, for example by comparing CFF results with other measures of CNS arousal and sedation, may be warranted.

Acknowledgements This study was supported by an unrestricted grant from Pfizer, New York. The authors wish to thank Anita van Oers, Karin Eikmans and Annette Heldens for their logistic support and data collection.

\section{References}

AufdemBrinke B (1982) The measurement of CFF: some methodological considerations. Pharmacopsychiatry 15:5-8

Benjamin J, Nemetz H, Fux M, Bleichman I, Agam G (1997) Acute inositol does not attenuate m-CPP-induced anxiety, mydriasis and endocrine effects in panic disorder. J Psychiatr Res 31:489-495

Broocks A, Little JT, Martin A, Minichiello MD, Dubbert B, Mack C, Tune L, Murphy DL, Sunderland T (1998) The influence of ondansetron and $\mathrm{m}$-chlorophenylpiperazine on scopolamine-induced cognitive, behavioral, and physiological responses in young healthy controls. Biol Psychiatry 43:408416

Clark WC (1966) The psyche in psychophysics: a sensory-decision analysis of the effect of instructions on flicker sensitivity and response bias. Psychol Bull 65:358-366

Curran S (1990) Critical Flicker Fusion techniques in psychopharmacology. In: Hindmarch I, Stonier PD (eds) Human psychopharmacology. Wiley, Chichester

Curran S, Wattis JP (1998) Critical Flicker Fusion threshold: a useful research tool in patients with Alzheimer's disease. Hum Psychopharmacol 13:337-355

Danjou P, Warot D, Hergueta T, Lacomblez L, Bouhours P, Puech AJ (1992) Comparative study of the psychomotor and antistress effects of ritanserin, alprazolam and diazepam in healthy subjects: some trait anxiety-independent responses. Int Clin Psychopharmacol 7:73-79

Davson H (1976) The eye. Academic Press, New York

Deijen JB, Loriaux SM, Orlebeke JF, De Vries J (1989) Effects of paroxetine and maprotiline on mood, perceptual-motor skills and eye movements in healthy volunteers. J Psychopharmacol $3: 148-155$

Ghozlan A (1990) Ascending-descending threshold differences and internal subjective judgement in CFF measures. Percept Mot Skills 70:1107-1110
Ghozlan A, Widlöcher D (1993) Ascending-descending threshold differences and internal subjective judgement in CFF measures of depressed patients before and after clinical improvement. Percept Mot Skills 77:435-439

Hart WM (1992) The temporal responsiveness of vision. In: Adler FH, Hart WM (eds) Adler's physiology of the eye. Mosby, St. Louis

Hindmarch I (1987) Antidepressant drugs and cognitive function. In: Biziere K, Garatinni S, Simon P (eds) Diagnosis and treatment of depression. Medsi/McGraw, Paris, pp 356-365

Hindmarch I (1995) The behavioural toxicity of the selective serotonin reuptake inhibitors. Int Clin Psychopharmacol 4:13-17

Hindmarch I (1998) The behavioural toxicity of antidepressants: effects on cognition and sexual function. Int Clin Psychopharmacol 13 [Suppl 6]:S5-S8

Hindmarch I (1999) Behavioural toxicity of antianxiety and antidepressant agents. Hum Psychopharmacol Clin Exp 14:137141

Hindmarch I, Bhatti JZ (1988) Psychopharmacological effects of sertraline in normal, healthy volunteers. Eur J Clin Pharmacol 35:221-223

Hindmarch I, Shillingford J, Shillingford C (1990) The effects of sertraline on psychomotor performance in elderly volunteers. J Clin Psychiatry 51:34-36

Kerr JS, Sherwood N, Hindmarch I (1991) The comparative psychopharmacology of 5HT reuptake inhibitors. Hum Psychopharmacol Clin Exp 6:313-317

Lawrence JR, McEwen J, Stonier PD, Pidgen AW (1982) Pupil size and Critical Flicker Fusion threshold: a reevaluation. Drug Dev Res Suppl 1:67-75

MacNab MW, Foltz EL, Sweitzer J (1985) Evaluation of signal detection theory on the effects of psychotropic drugs on critical flicker-fusion frequency in normal subjects. Psychopharmacology 85:431-435

Mattila MJ, Saarialho-Kere U, Mattila M (1988) Acute effects of sertraline, amitriptyline, and placebo on the psychomotor performance of healthy subjects over 50 years of age. J Clin Psychiatry 49:52-58

Miles PW (1950) Flicker fusion fields, effects of age and pupil size. Am J Ophthalmol 33:769-772

Millson DS, Haworth SJ, Rushton A, Wilkinson D, Hobson S, Harry J (1991) The effects of a 5-HT2 receptor antagonist (ICI 169,369) on changes in waking EEG, pupillary responses and state of arousal in human volunteers. Br J Clin Pharmacol $32: 447-54$

Millson DS, Jessup CL, Swaisland A, Haworth S, Rushton A, Harry JD (1992) The effects of a selective 5-HT2 receptor antagonist (ICI 170,809) on platelet aggregation and pupillary responses in healthy volunteers. Br J Clin Pharmacol 33:281288

Nathan PJ, Stough C, Siteram G (2000) Serotonin and information processing: a pharmacological study on the effects of citalopram on cognitive and psychomotor function. Hum Psychopharmacol 15:306-307

Penn JS, Anderson RE (1991) Effects of light history on the rat retina. In: Osborne NN, Chader GJ (eds) Progress in retinal research. Pergamon Press, Oxford

Prow MR, Martin KF, Heal DJ (1996) 8-OH-DPAT-induced mydriasis in mice: a pharmacological characterisation. Eur J Pharmacol 317:21-28

Ramaekers JG, Muntjewerff ND, O'Hanlon JF (1995) A comparative study of acute and subchronic effects of dothiepin, fluoxetine and placebo on psychomotor and actual driving performance. Br J Clin Pharmacol 39:397-404

Ripps H, Weale RA (1976) Temporal analysis and resolution In: Davson H (ed) The eye. Academic Press, New York

Rizzi CA, Prudentino A, Giraldo E (1993) Effects on general behaviour and neurotransmitter functions of a new 5-hydroxytryptamine 3 receptor antagonist with potential relevance in central nervous system disturbances. Arzneimittelforschung 43:1033-1041 
Saletu B, Grünberger J (1988) Drug profiling by computed electroencephalography and brain maps, with special consideration of sertraline and its psychometric effects. J Clin Psychiatry 49:59-71

Schmitt JAJ, Riedel WJ (1999) Serotonergic antidepressants effects on vigilance and cognition. Eur Neuropsychopharmacol 9:S241

Smith JM, Misiak H (1976) Critical Flicker Frequency (CFF) and psychotropic drugs in normal human subjects: a review. Psychopharmacology 47:175-182

Swets JA, Tanner WP, Birdsall TG (1961) Decision processes in perception. Psychol Rev 68:301-340
Szabadi E, Bradshaw CM (1996) Autonomic pharmacology of alpha2-adrenoceptors. J Psychopharmacol 10:6-18

Warrington SJ, Dana-Haeri J, Sinclair AJ (1989) Cardiovascular and psychomotor effects of repeated doses of paroxetine: a comparison with amitriptyline and placebo in healthy men. Acta Psychiatr Scand 80:42-44

Williams SA, Wesnes K, Oliver SD, Rapeport WG (1996) Absence of effect of sertraline on time-based sensitization of cognitive impairment with haloperidol. J Clin Psychiatry $1: 7-11$

Zung WWK (1965) A self rating depression scale. Arch Gen Psychiatry $12: 63-70$ 